\title{
Peningkatan Aktivitas Fisik dan Pemanfaatan Pekarangan Rumah untuk Tanaman Sayuran dan Buah sebagai Gerakan Masyarakat Hidup Sehat (Germas) di Desa Penyengat Olak Kecamatan Jambi Luar Kota
}

\author{
Suryani $^{1}$, Neni Heryani ${ }^{2}$, Indarmien Netty Ariasih ${ }^{3}$ \\ 1,2,3 Jurusan Kebidanan Poltekkes Kemenkes Jambi \\ Email: suryaniraesya@gmail.com
}

Submitted : 31/12/2020

Accepted: 03/01/2021

Published: 11/01/2021

\begin{abstract}
According to the World Health Organization, the prevalence of anemia in the world ranges from 40-88\%. The number of pregnant women (10-19 years) in Indonesia is $26.2 \%$, consisting of $50.9 \%$ men and $49.1 \%$ women. The prevalence of anemia in pregnant women in Muaro Jambi has been reported by Kalsum and Halim in 2015 were 67\% with the main cause being the lack of the habit of having breakfast. Isaati in 2014 also reported the prevalence of anemia among pregnant women in Jambi City, which was 78.7\% due to the lack of frequency of eating, consumption of tea, coffee and consumption of iron-enhancing foods. Even though Germas was only launched in 2017, it needs initiation starting from the smallest community groups such as dasa wisma, groups of pregnant women. This Community Service activity will focus on 3 Germas sub-activities, namely increasing physical activity for pregnant women, namely pregnancy exercise. Health checks with tension checks on pregnant women, counseling with the theme of nutritious eating for pregnant women, and utilization of house yards for vegetables and fruit plants. This activity has been carried out through community mobilization, especially for pregnant women in the work area of the Penyengat Olak Health Center, to get involved from planning to evaluation of activities. So that counseling and tension checks can be carried out on October 26, 2020, as many as 20 pregnant women from 4 villages, with pregnancy exercises and ending the distribution of vegetable and fruit crops.
\end{abstract}

Keywords: pregnant women, physical activity, utilization of the yard

\begin{abstract}
Abstrak
Menurut World Health Organization, prevalensi anemia dunia berkisar 40-88\%. Jumlah usia ibu hamil (10-19 tahun) di Indonesia sebanyak 26,2\% yaitu terdiri dari 50,9\% laki-laki dan 49,1\% perempuan. Prevalensi anemia pada ibu hamil di Muaro Jambi telah dilaporkan oleh Kalsum dan Halim tahun 2015 yaitu 67\% dengan penyebab utama adalah kurangnya kebiasaan sarapan pagi. Isaati tahun 2014 juga melaporkan prevalensi penderita anemia pada ibu hamil di Kota Jambi yaitu sebesar 78,7\% dengan penyebab frekuensi makan yang kurang, konsumsi teh, kopi dan konsumsi makanan peningkat $\mathrm{Fe}$ yang kurang. Meskipun Germas baru dicanangkan pada tahun 2017, perlu dilakukan inisiasi mulai dari kelompok masyarakat paling kecil seperti dasa wisma, kelompok ibu hamil. Kegiatan Pengabdian ini akan fokus pada 3 sub-kegiatan Germas, yaitu peningkatan aktivitas fisik untuk ibu hamil adalah senam hamil. Pemeriksaan Kesehatan dengan pemeriksaan dengan tensi pada ibu hamil, penyuluhan dengan tema makan bergizi pada ibu hamil, dan pemanfaatan pekarangan rumah untuk tanaman sayur dan buah. Kegiatan ini sudah dilakukan melalui mobilisasi masyarakat khususnya pada ibu hamil di wilayah kerja Puskesmas Penyengat Olak, untuk ikut terlibat mulai dari perencanaan hingga evaluasi kegiatan. Sehingga dapat terlaksana penyuluhan dan pemeriksaan tensi pada tanggal 26 Oktober 2020 sebanyak 20 ibu Hamil dari 4 desa, dengan senam hamil dan diakhiri pembagian tanaman sayur dan buah,
\end{abstract}

Kata Kunci: aktifitas fisik, ibu hamil, pemanfaatan pekarangan

\section{PENDAHULUAN}

Negara berkembang, menghadapi beban ganda penyakit menular dan penyakit tidak menular (PTM). Beberapa target dalam penyelesaian masalah penyakit menular maupun penyakit tidak menular 
telah dimasukkan ke dalam agenda global seperti Millenium Development Goals (MDGs). Namun, hingga akhir pencapaian target MDGs tahun 2015, banyak negara yang belum mampu untuk mencapai target yang telah ditetapkan. Setelah tahun 2015, agenda global baru pun dicanangkan, yaitu Sustainable Development Goals (SDGs). SDGs masih menargetkan beberapa indikator terkait dengan penyakit menular, penyakit tidak menular, dan termasuk juga universal health coverage yang akan dicapai tahun 2030.

Berkaca dari kegagalan sebagian besar negara dalam mencapai target MDGs, pencapaian target SDGs menjadi suatu tantangan besar dalam pembangunan kesehatan. Oleh sebab itu, layanan kesehatan yang disediakan untuk masyarakat harus paripurna. Penyediaan layanan kuratif dan perlindungan finansial pada masyarakat untuk menggunakan layanan kuratif telah ditingkatkan. Adapun yang menjadi pertanyaan adalah, dimana posisi upaya promosi kesehatan dan pencegahan penyakit saat ini? Kedua upaya ini harus lebih dioptimalkan dan dilakukan langkah penguatan.

Penguatan upaya pencegahan penyakit akan memberikan keuntungan yang luar biasa. Promosi kesehatan dan pencegahan penyakit merupakan investasi utama untuk mengurangi beban negara dalam membiayai layanan kesehatan bagi masyarakat. Negara berkembang sangat merasakan beban ini dikarenakan keterbatasan anggaran dan ancaman keberlanjutan anggaran, terutama penyakit tidak menular yang memerlukan pengobatan mahal dan jangka panjang.

Upaya pencegahan penyakit, ataupun deteksi dini pada ibu hamil memiliki karakteristik yang berbeda dengan upaya, preventif, kuratif, karena manfaatnya tidak didapatkan dalam waktu dekat, namun akan dirasakan setelah jangka panjang. Karakteristik inilah yang menjadikan upaya promosi kesehatan dan pencegahan penyakit oleh masyarakat sulit untuk dilaksanakan terus menerus. Oleh sebab itu, promosi kesehatan dan pencegahan penyakit yang bersifat topdown dari pemerintah tidak efektif lagi, karena masyarakat tidak merasa menjadi bagian dari program.

Banyak studi yang menemukan bahwa upaya promosi kesehatan dan pencegahan penyakit yang berbasis komunitas lebih efektif (Watson-Thompson et al. 2008). Oleh sebab itu, pemerintah Indonesia mencanangkan Gerakan Masyarakat Hidup Sehat (GERMAS), berupa upaya promosi kesehatan dan pencegahan penyakit yang menekankan masyarakat sebagai aktor utama. GERMAS memiliki enam kegiatan utama, yaitu peningkatan aktivitas fisik, peningkatan perilaku hidup sehat, penyediaan pangan sehat dan percepatan perbaikan gizi, peningkatan pencegahan dan deteksi dini penyakit; peningkatan kualitas lingkungan, dan peningkatan edukasi hidup sehat.

Pencegahan penyakit dan promosi kesehatan merupakan upaya esensial di saat masih tingginya kejadian penyakit menular juga diiringi dengan semakin meningkatnya masalah penyakit tidak menular. Semakin tingginya beban masalah kesehatan masyarakat saat ini, khususnya pada ibu hamil mengindikasikan bahwa promosi kesehatan dan pencegahan yang telah ada kurang dapat berkontribusi dalam meningkatkan derajat kesehatan masyarakat. Banyak studi yang menemukan bahwa upaya promosi kesehatan dan pencegahan penyakit yang bersifat topdown dari pemerintah, kurang efektif bila dibandingkan dengan program yang berbasis masyarakat. Oleh sebab itu, untuk mendukung Gerakan Masyarakat Hidup Sehat (GERMAS) yang baru dicanangkan oleh pemerintah, perlu dilakukan mobilisasi masyarakat dalam membiasakan hidup sehat sesuai dengan tujuan program Germas Desa Penyengat Olak Kecamatan Jambi Luar kota Kabupaten Muaro Jambi, belum 
dilakukan promosi kesehatan dan pencegahan penyakit yang berbasis masyarakat khususnya bagi ibu hamil, saat ini belum ada kegiatan kelas ibu hamil.. Bila dikaitkan dengan Germas, perlu dilakukan inisiasi promosi kesehatan dan pencegahan penyakit, deteksi dini pada ibu hamil, yang berbasis masyarakat.

\section{TARGET DAN LUARAN}

1. Target

Kontribusi mendasar dari kegiatan ini adalah peningkatan kemampuan masyarakat dalam merencanakan, melaksanakan dan mengevaluasi upaya promosi kesehatan dan pencegahan penyakit yang dilakukan secara mandiri dan sesuai dengan kebutuhan kesehatan masyarakat di Desa Penyengat Olak Kecamatan Jambi Luar Kota Kabupaten Muaro Jambi.

2. Luaran

Target luaran dari kegiatan ini adalah dilaksanakannya Gerakan Masyarakat Hidup Sehat (GERMAS) melalui peningkatan aktivitas fisik dan pemanfaatan pekarangan rumah untuk tanaman sayur dan buah di Desa Penyengat Olak Kecamatan Jambi Luar Kota Kabupaten Muaro Jambi.

\section{METODE PELAKSANAAN}

1. Persiapan meliputi perijinan dan pengajuan proposal kepada Kepala Puskesmas dan pada bidan koordinator Penyengat Olak. Melakukan studi pustaka tentang program Germas, ini merupakan Tahap Pertama Tahap pertama merupakan perencanaan kegiatan yang akan dilakukan perijinan. Proses perencanaan meliputi identifikasi kebutuhan, identifikasi potensi dan kelemahan yang ada, menentukan jalan keluar dan kegiatan yang akan dilakukan, dan membuat pengorganisasian kegiatan. Perencanaan disusun sendiri oleh masyarakat. Sedangkan tim pengabdian dan petugas Puskesmas akan bertindak sebagai fasilitator.

2. Melakukan studi pustaka tentang program TTD, Pemeriksaan $\mathrm{Hb}$ pada ibu hamil untuk mengetahui ada tidaknya anemi.

3. Melaksanakan orentasi tempat penjual sayur dan buah yang akan dibagikan .

4. Menjelaskan rencana kegiatan kepada , Kepala Puskesmas, bidan koordinator di Desa Penyengat Olak.

5. Menganalisa situasi ibu hamil di Desa Penyengat Olak dan menentukan masalah

6. Mengidentifikasi ibu hamil yang akan menjadi sasaran kegiatan dan waktu yang akan diperlukan untuk menyelesaikan kegiatan.

7. Melakukan studi pustaka tentang program Germas, TTD, anemi

8. Menyiapkan saran dan prasarana yang akan digunakan

9. Penjajagan ke wilayah kerja Puskesmas Penyengat Olak

10. Menentukan waktu untuk pelaksanaan pengabdian masyarakat Bersama penanggung jawab

11. Menentukan dan mempersiapkan materi yang akan disampaikan dalam kegiatan pengabdian masyarakat

12. Pelaksanaan pengabdian masyarakat berlangsung slma tiga kali dengan jumlah peserta $40 \mathrm{ibu}$ hamil.

13. Diawali dengan perkenalan, penyampaian maksud dan tujuan, kemudian secara jujur siapa yang minum TTD sesuai anjuran sampai habis ternyata hanya ada beberapa ibu hamil yang minum secara teratur, penyuluhan dilanjutkan pentingnya pemeriksaan $\mathrm{HB}$, senam ibu hamil, dan penanaman sayur, buah di pekarangan.

14. Menentukan tujuan kerja 
15. Melalui bidan koordinator memberikan pengumuman dan melakukan pendekatan kepada ibu hamil.

16. Pelaksanakan kegiatan dengan melibatkan mahasiswa dalam pelaksanaan kegiatan sosialisasi Germas, pemeriksaan HB, senam Hamil dan penanaman sayur dan buah di pekarangan. Kegiatan dilaksanakan bersama sama oleh masyarakat sesuai dengan yang telah direncanakan. Sedangkan tim pengabdian dan petugas Puskesmas akan bertindak sebagai fasilitator.

17. Adanya Kesepakatan Bersama untuk minum $\mathrm{Fe}$ sehabis makan malam sebelum tidur.

18. Evaluasi hasil kegiatan dengan tanya jawab, adanya kesediaan menjadi pelaksana Germas di rumah tangga masing masing. , minum $\mathrm{Fe}$ setiap hari .

\section{HASIL DAN PEMBAHASAN}

Kegiatan Pengabdian masyarakat telah dilaksanakan dengan tiga tahap : Tahap pertama Penjajakan kepada kepala Puskesmas, bidan koordinator. Pelaksanaan pada tanggal 1/9/2020 adanya penyuluhan tentang Germas, pentingnya $\mathrm{Fe}$ pada ibu hamil, pentingnya kepatuhan minum $\mathrm{Fe}$ selama kehamilan, dan pemeriksaan Tensi darah sebanyak 25 orang ibu hamil.

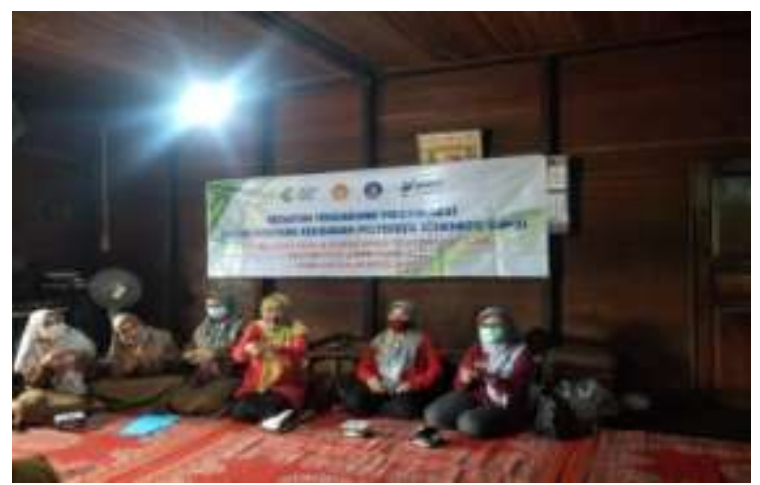

Gambar 1. Pelaksanaan penyuluhan pada ibu hamil

Tahap kedua pada tanggal 18 $/ 10 / 2020$ adanya penyuluhan tentang
Germas, pentingnya makan sayur danbuah pada ibu hamil, dan pemeriksaan Tensi darah sebanyak 25 ibu hamil.

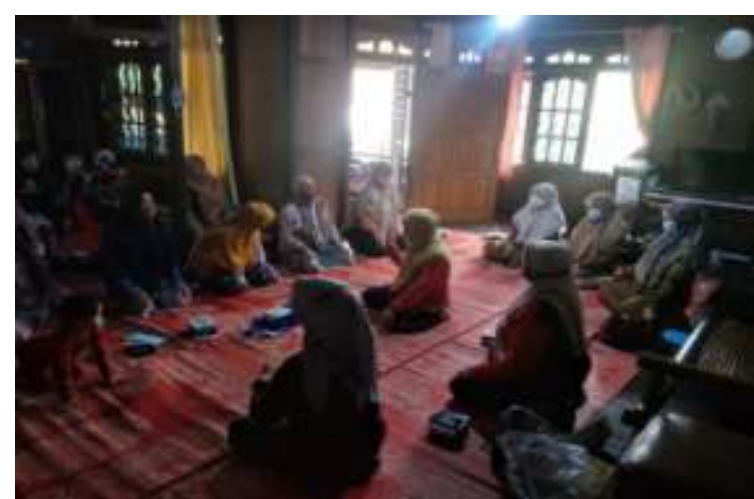

Gambar 2. Penjelasan tentang pemanfaatan pekarangan

Tahap ketiga pada tanggal 26/10/2020. Pelaksanaan Kegiatan pengabdian ini telah dilakukan penyuluhan, senam hamil dan pembagian sayur dan tanaman buah yang akan ditanam di pekarangan masing masing ibu hamil.

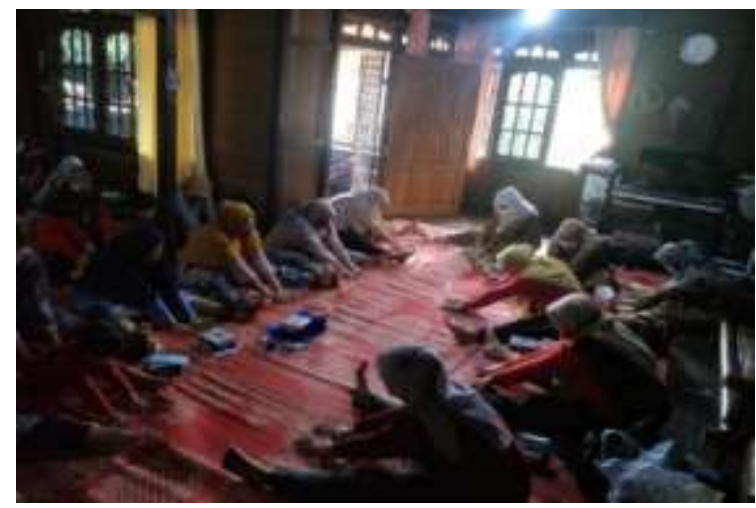

Gambar 3. Pelaksanaan senam hamil

Meskipun Germas baru dicanangkan pada tahun 2017, perlu dilakukan inisiasi mulai dari kelompok masyarakat paling kecil seperti dasa wisma. Kegiatan Pengabdian ini akan fokus pada 3 subkegiatan Germas, yaitu pemeriksaan kesehatan, peningkatan aktivitas fisik dan pemanfaatan pekarangan rumah untuk tanaman sayur dan buah. Kegiatan ini akan dilakukan melalui mobilisasi masyarakat untuk ikut terlibat mulai dari perencanaan hingga evaluasi kegiatan. Sehingga dapat diharapkan agar program ini akan terus 
berlanjut secara swadaya oleh masyarakat meskipun kegiatan pengabdian telah selesai. Dengan mengadakan penyuluhan agar ibu hamil melakukan pemeriksaan $\mathrm{Hb}$, melalui kombinasi penyuluhan dan konseling, sebanyak 25 ibu hamil yang sudah memeriksakan $\mathrm{HB}$, diketahui ada yang masih anemi. Namun yang ikut senam hamil hanya ada $14 \mathrm{ibu}$ hamil, dan pembagian tanaman sayur dan bibit buah semua ibu hamil dapat serta membiasakan makan buah dan sayur.

Hasil kegiatan pengabdian masyarakat ini yaitu adanya peningkatan kemampuan masyarakat khususnya pada ibu hamil dalam melaksanakan Germas, mulai merencanakan, melaksanakan dan mengevaluasi upaya promosi kesehatan dan pencegahan penyakit yang dilakukan secara mandiri dan sesuai dengan kebutuhan masyarakat setempat. Adanya peningkatan aktivitas fisik dan pemanfaatan perkarangan rumah untuk tanaman sayuran dan buah. Kegiatan ini dilakukan melalui mobilisasi masyarakat untuk ikut terlibat mulai perencaana hingga evaluasi kegiatan. Harapan pengabdi program ini akan terus berlanjut secara swadaya oleh masyarakat meskipun kegiatan pengabdian telah selesai.

Beberapa hasil kegiatan pengabdian masyarakat yang sudah dicapai adalah terbentuknya kelompok masyarakat yang mampu secara mandiri melaksanakan Germas, mulai merencanakan, melaksanakan dan mengevaluasi upaya promosi kesehatan dan pencegahan penyakit yang dilakukan secara mandiri dan sesuai dengan kebutuhan masyarakat setempat di desa Penyengat Olak Kecamatan Jambi Luar Kota Kabupaten Muaro Jambi

Adanya pemanfaatan perkarangan rumah untuk tanaman sayuran dan buah serta artikel ilmiah pada jurnal pengabdian masyarakat nasional tidak terakreditasi.

\section{KESIMPULAN DAN SARAN}

\section{Kesimpulan}

a. Kegiatan Aktivitas Fisik Dan Pemanfaatan Perkarangan Rumah Untuk Tanaman Sayuran Dan Buah Sebagai Gerakan Masyarakat Hidup Sehat Di Desa Penyengat Olak Kecamatan Jambi Luar Kota Kabupaten Muaro Jambi 2020

b. Adanya peningkatan kemampuan masyarakat khususnya pada ibu hamil dalam melaksanakan Germas.

c. Masyarakat khususnya ibu hamil dapat memberdayakan dirinya seperti menanam buah dan sayur minimal untuk konsumi keluarga, serta berdaya dalam memelihara Kesehatan diri dan bayinya.

\section{Saran}

Perlu tindak lanjut kegiatan yang dilakukan oleh Kader, Tokoh masyarakat sehingga kegiatan ini dapat terus berlangsung secara swadaya oleh masyarakat. Perlu adanya Inovasi baru dalam pemberdayaan masyarakat khususnya Ibu hamil dalam peningkatan kegiatan aktivitas fisik dan pemanfaatan perkarangan rumah.

\section{UCAPAN TERIMAKASIH}

Ucapan terima kasih kepada masyarakat terutama kepada ibu hamil, kader, Kepala Desa dan Institusi terkait kegiatan Pengabdian yang dilaksanakan.

\section{DAFTAR PUSTAKA}

Beaglehole R,at all. 2011. Priority actions for the non-communicable disease crisis. The Lancet 377: 1438-1447.

Coleman MP et al. (2008). Cancer survival in five continents: a worldwide populationbased study (CONCORD). Lancet Oncol, 9, 730-56.

Habib SH, Saha S. 2010. Burden of noncommunicable disease: Global overview. Diabetes \& Metabolic 
Jurnal Abdimas Kesehatan (JAK) Vol 3, No 1, Januari 2021

Doi : $10.36565 /$ jak.v3i1.192

p-ISSN: 2655-9266

e-ISSN: 2655-9218

Syndrome: Clinical Research \& Reviews 4: 41-47.

health data. The Lancet 367: 174757.

Kemenkes RI. 2015. Stop Kanker. Jakarta: Kemenkes RI.

WHO. 2015. Noncommunicable Diseases: Fact Sheet [Diakses 27 Oktober 2020].

Lopez AD, Mathers CD, Ezzati M, Jamison DT, Murray CJL. 2006. Global and regional burden of disease and risk factors, 2001: systematic analysis of population

WHO. 2016. Breast Cancer: Prevention and Control [Diakses 27 Oktober 2020]. 